\section{Optic nerve head structure in glaucoma: astrocytes as mediators of axonal damage}

\begin{abstract}
Increased intraocular pressure (IOP) is recognised as the principal risk factor for the development of glaucomatous cupping of the optic disc. The hypothesis that it disrupts the function of retinal ganglion cell axons by increasing mechanical forces on the lamina cribrosa of the optic nerve head has received considerable experimental support. However, many patients with glaucoma will have progressive cupping even though the IOPs remain within the normal range, suggesting that mechanical compression is unlikely to be the sole cause of optic nerve damage. Clinical studies have emphasised the role of other factors, such as optic nerve head ischaemia, in generating optic disc cupping. One of the outstanding problems in understanding optic nerve head dysfunction in glaucoma has been the elucidation of the pathways that could integrate the effects of IOP and ischaemia to generate the characteristic changes seen. This review considers the role that optic nerve head astrocytes might play in the initiation of axon damage, based on the hypothesis that these cells are sensitive to mechanical or ischaemic

events are easily discernible in the clinical assessment of the optic disc their underlying pathophysiology remains obscure. The puzzle of glaucomatous optic disc cupping is that, although raised intraocular pressure (IOP) remains the most important causative factor and the focus for most clinical treatments, many glaucoma patients have IOPs within the normal range. Conversely, most eyes with IOPs above $21 \mathrm{mmHg}$ do not develop glaucoma, with some optic discs apparently resisting damage at IOPs close to $30 \mathrm{mmHg}$.

These observations stress the importance of considering other factors, besides IOP, that will cause optic disc cupping. This is a daunting task, in view of the complexity of optic nerve structure, but recent advances in our understanding of the interactions between neural and glial elements in the central nervous system are now providing valuable insights into how damage to retinal ganglion cell axons may be initiated. This review will consider these interactions and try to place them in the context of our current understanding of glaucomatous optic neuropathy.
\end{abstract} factors and are important for the maintenance of retinal ganglion physiology. It discusses their role in the remodelling of the structure of the lamina cribrosa and the effect that this might have on axon function. Recent evidence has shown that the modulation of astrocyte activity, for example by the reduction of the production of nitric oxide, may prevent retinal ganglion cell death in ocular hypertension. The possibility that astrocyte-axon interactions are important in the development of glaucomatous optic neuropathy suggests new avenues of therapeutic intervention, not related to the control of IOP, that would prevent retinal ganglion cell death in glaucoma.

Key words Astrocyte, Glaucoma, Glia, Lamina cribrosa, Optic nerve, Retinal ganglion cell

Glaucomatous optic neuropathy is characterised by cupping of the optic disc and thinning of the neuroretinal rim. While these
The histopathology of glaucomatous optic neuropathy

Many of the details of the pathophysiological processes involved in optic nerve cupping have come from animal models of ocular hypertension. These models address the pressure-related component of optic disc damage but provide optic disc changes that are very similar to those seen in human disease. In general, they have confirmed that axonal damage is most probably initiated within the optic nerve head. In experimental ocular hypertension, obstruction of axoplasmic transport is seen at the level of the lamina cribrosa $^{1-5}$ reducing the delivery of neurotrophic factors necessary for retinal ganglion cell survival. ${ }^{6}$ In turn, this predisposes to neuronal loss by programmed cell death, which has been demonstrated to occur in both rodent and primate glaucoma models ${ }^{7,8}$ as well as in humans. ${ }^{9}$

\section{J.E. Morgan \\ Department of Ophthalmology University of Wales College of Medicine Cardiff CF4 4XW, UK}

James E. Morgan, DPhil, FRCOphth

Department of

Ophthalmology

University Hospital of Wales

Heath Park

Cardiff CF4 4XW, UK

Tel: +44 (0)29 20744970

Fax: +44 (0)29 20743222

e-mail:

morganje3@cardiff.ac.uk 

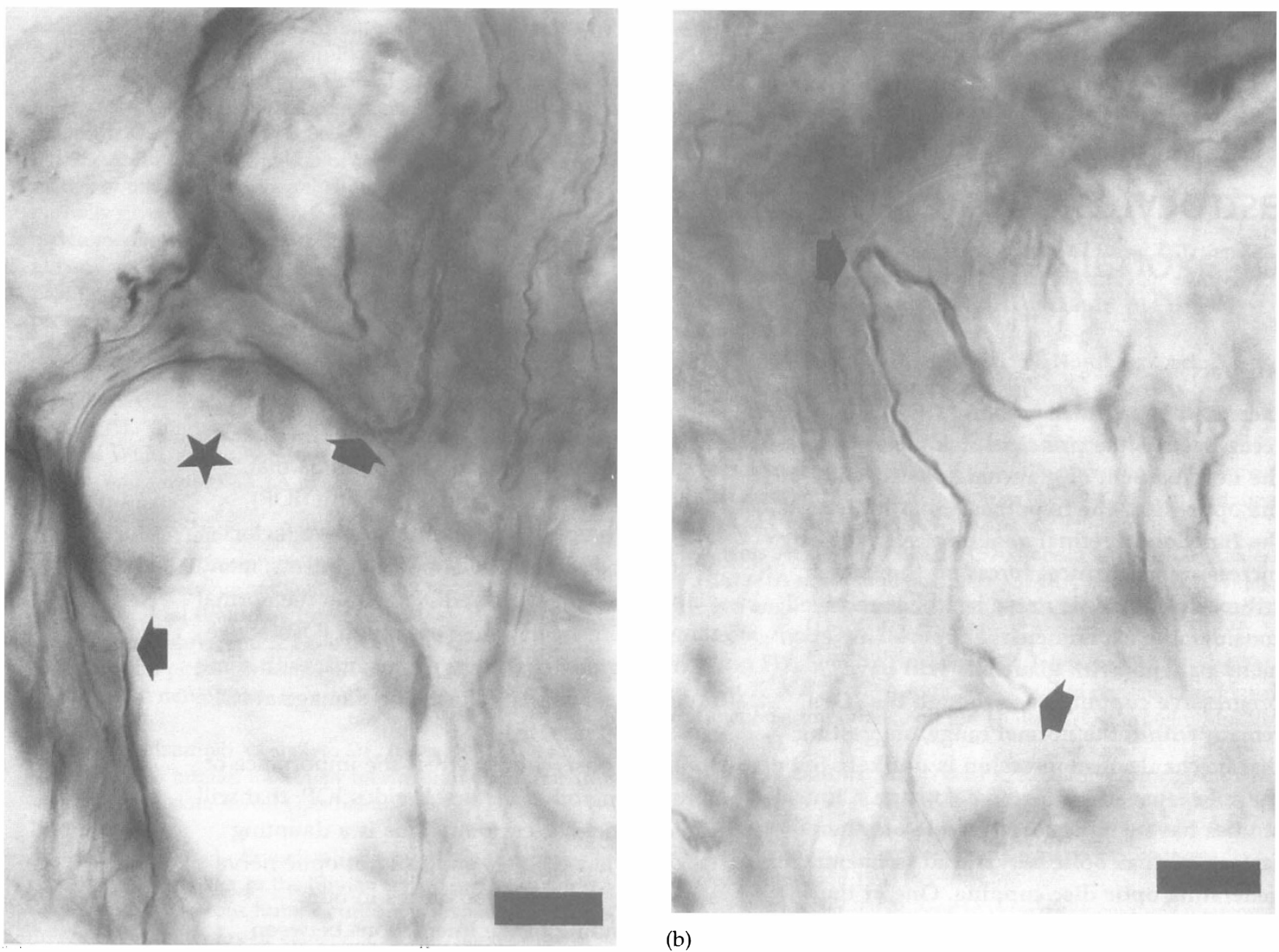

(b)

(a)

Fig. 1. (a) Horseradish peroxidase (HRP)-labelled retinal ganglion cell axons in the human optic nerve head at the level of the lamina cribrosa. The asterisk shows the location of the cribrosal plate. Arrows highlight the axon of interest. Scale bar represents $2 \mu m$. (b) HRP-labelled axon as for (a). Arrows highlight deflections in the axon of interest. Scale bar represents $2 \mu \mathrm{m}$. From Morgan et al. ${ }^{14}$

The evidence that similar processes occur in human glaucomatous optic neuropathy is considerable. Studies of the lamina cribrosa in glaucoma patients have shown collapse and rotation of the plates of the lamina cribrosa $^{10,11}$ which would distort axon paths, interrupt axonal transport ${ }^{12,13}$ and predispose to cell death, probably by apoptosis. ${ }^{8,9}$ The finding that these changes are greater at the superior and inferior poles of the optic disc has been attributed to a reduced density of cribrosal beams, which may explain the preferential pathological loss of axons in these parts of the nerve. ${ }^{12}$ Tracing experiments in the human have shown that some axons may be particularly vulnerable to the effects of distortion of the lamina cribrosa since they do not take a direct route through the optic nerve head but deviate to pass between the plates of the scleral lamina ${ }^{14}$ (Fig. 1). This observation is consistent with the finding that the number of cribrosal pores increases by 50\% from the choroidal to the scleral part of the lamina, ${ }^{15}$ necessitating some deviation in axon paths in the more posterior parts of the optic nerve head. The lamina cribrosa is also thicker in the peripheral parts of the nerve, effectively increasing the length of the path taken by these axons through the optic nerve head ${ }^{16}$ - and possibly increasing the risk of mechanical damage.
While simple axonal compression is an appealing concept, other studies suggest a more complex relationship between cribrosal structure and axon loss. In experimental primate glaucoma, the block to axoplasmic transport occurs at the level of the scleral lamina where the cribrosal pores are smaller and have more interpore tissue, ${ }^{15}$ an observation that would not account for the preferential nerve damage at the disc poles.

Consideration of the pattern of progressive visual field loss in relation to changes in the optic nerve head also reveals some interesting anomalies. If greater rotation and distortion of the cribrosal beams at the periphery of the optic disc accounts for the periphery-to-centre progression of visual field loss in glaucoma it implies a precise vertical segregation of axons within the retinal nerve fibre layer based on eccentricity. ${ }^{17}$ Rotation of the lamina cribrosa at the edge of the optic nerve head would cause greater damage to axons from peripheral retinal ganglion cells. Some studies report a precise vertical segregation of axons within the retinal nerve fibre layer based on the eccentricity of their cell of origin, ${ }^{18-20}$ but others have shown considerable rearrangement of axons within the optic nerve head (Fig. 2) ${ }^{21,22}$ and retrobulbar optic nerve ${ }^{23}$ (Fig. 3). Evidence for a coarse vertical topographic segregation questions the basis for the centripetal progression of visual field defects that is 


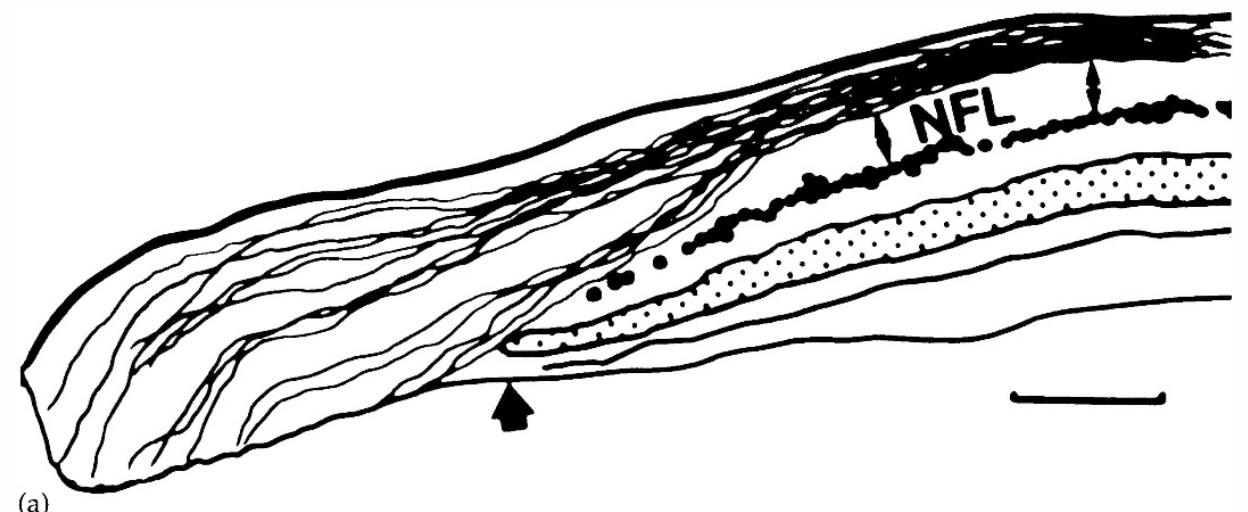

(a)
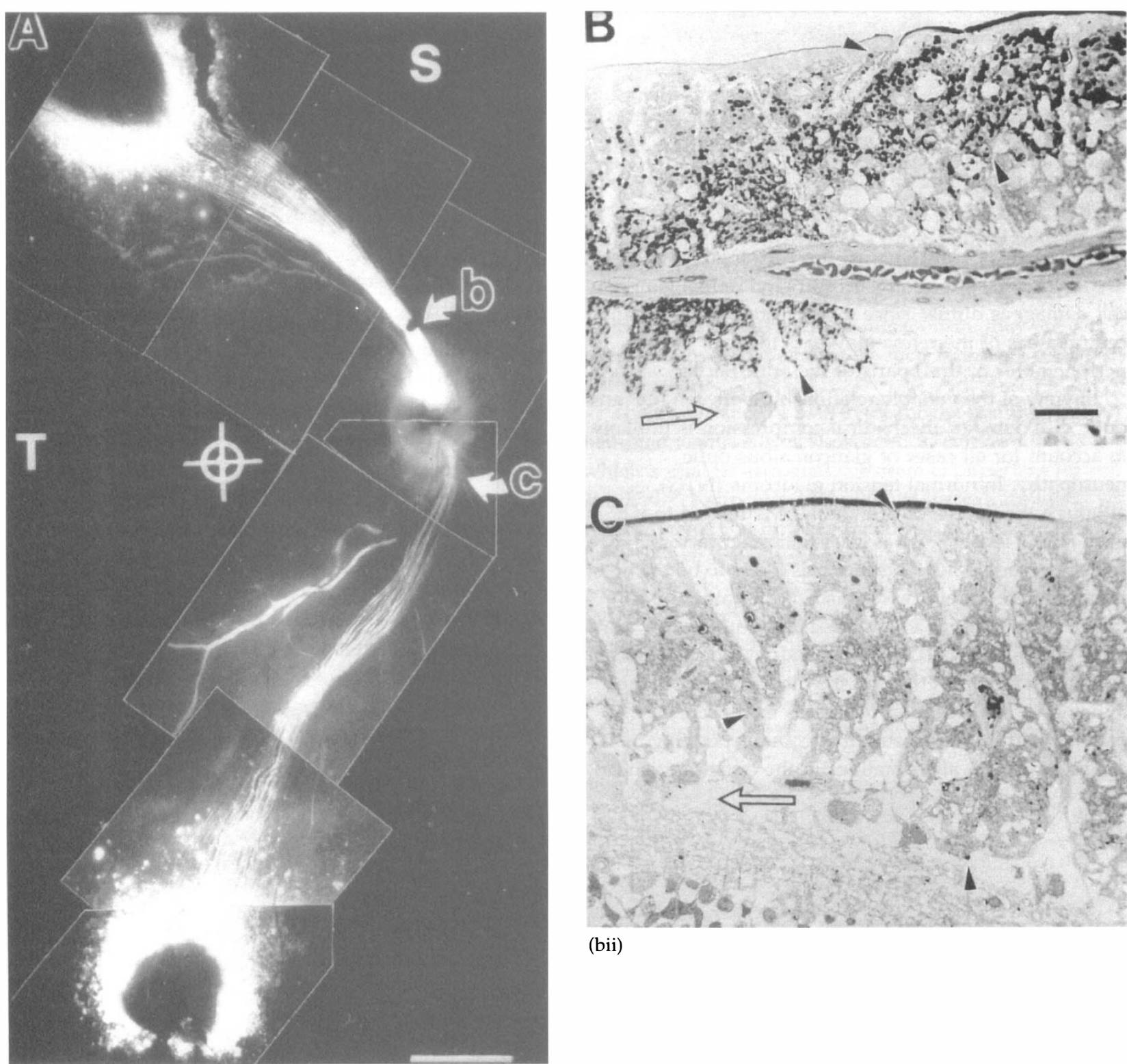

(bii)

(bi)

Fig. 2. Camera lucida drawing of the course taken by individual axons at the margin of the optic disc. Axons from more peripheral retinal ganglion cells pass on the vitreal side of those from cells closer to the optic disc. NFL, nerve fibre layer. The large filled arrow marks the edge of the optic disc. Scale bar represents $100 \mu \mathrm{m}$. From Ogden. ${ }^{22}$ (b) (i) Course taken by axons towards the human optic nerve head. Axons have been labelled using the tracer Dil applied to post-mortem tissue. Scale bar represents $2 \mathrm{~mm}$. (ii) Upper photomicrograph shows a cross-section through the retinal nerve fibre layer corresponding to region (b) in (i). Axons that have been labelled at one retinal location are distributed throughout the vertical extent of the nerve fibre layer. A similar scattered distribution of axons is seen at the inferior aspect of the optic disc (c). Scale bar represents $25 \mu \mathrm{m}$. From Fitzgibbon and Taylor. ${ }^{21}$ 


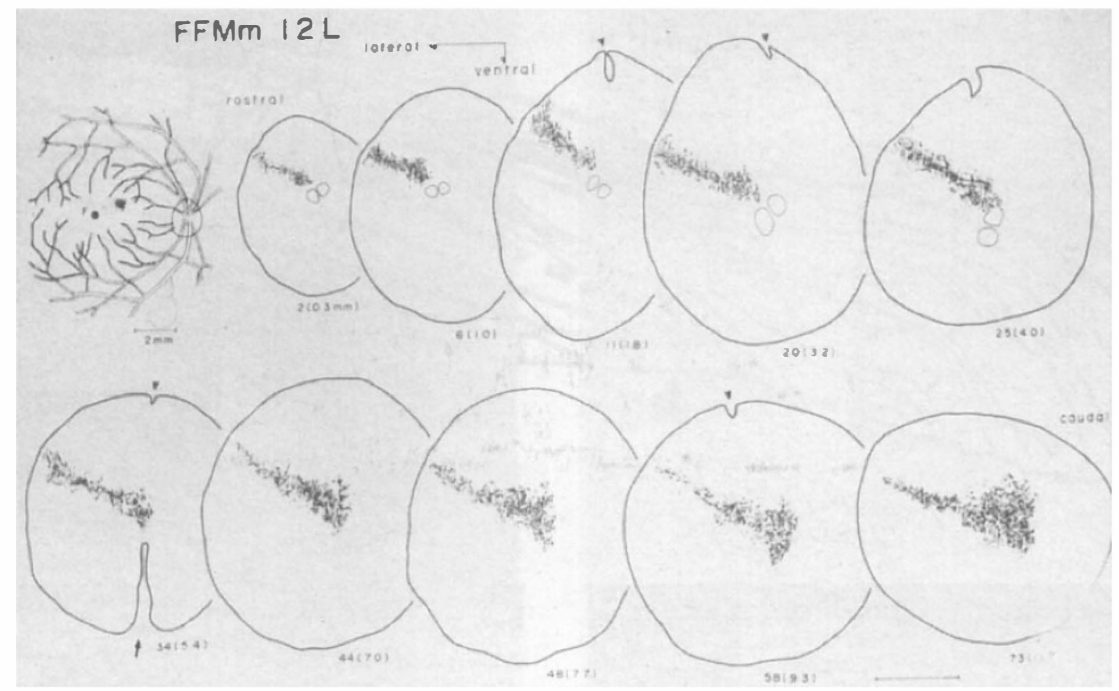

Fig. 3. Camera lucida drawings showing the distribution of axons labelled with WGA-HRP following injection into the right lateral geniculate nucleus. The left optic nerve and retina are shown. Shading in the retinal diagram shows the location of retinal ganglion cells labelled by retrograde transport of WGA-HRP. Note the scatter of fibres from the centre to the periphery of the nerve that corresponds to a small region of labelling in the retina. From Naito. ${ }^{23}$

characteristic of glaucoma. At the very least it suggests that, with regard to retinal eccentricity, retinal ganglion cell damage is diffuse since axons from peripheral and central areas of the retina may pass through the peripheral (or central) parts of the optic nerve.

In view of the variable relationship between IOP and optic disc damage, mechanical compression is unlikely to account for all cases of glaucomatous optic neuropathy. In normal tension glaucoma (NTG), although the degree of disc damage is related to IOP even at low levels, ${ }^{24,25}$ it is clear that other factors play a role. Optic nerve head perfusion is likely to be the most important. Peripheral vasospasm, ${ }^{26}$ migraine ${ }^{27}$ and nocturnal reductions in systemic blood pressure ${ }^{28}$ are more common in NTG patients and would be expected to have an adverse effect on the blood supply to the optic nerve head. Similar processes may occur in patients with high-pressure glaucoma, ${ }^{29}$ possibly in conjunction with abnormalities in the optic nerve head blood flow. ${ }^{30}$ In experimental models, reduction of optic nerve head blood flow can be induced by endothelin infusion, ${ }^{31,32}$ resulting in axon loss. In NTG there is evidence that endothelin-1-mediated vascular regulation may also be abnormal. ${ }^{33}$

These considerations suggest that the ischaemic and mechanical factors causing optic nerve head damage are not mutually exclusive. Insults to optic nerve axons can be mechanistic or ischaemic and form part of a continuous and, possibly, additive process that interacts with the underlying structure of the optic nerve. The key issue is how these factors generate the characteristic appearance of the glaucomatous optic disc. Recent evidence suggests that optic nerve head astrocytes, which have long been recognised as important components of the optic nerve head, ${ }^{34,35}$ may underlie this process and be central to the initiation of glaucomatous optic neuropathy. ${ }^{36-38}$

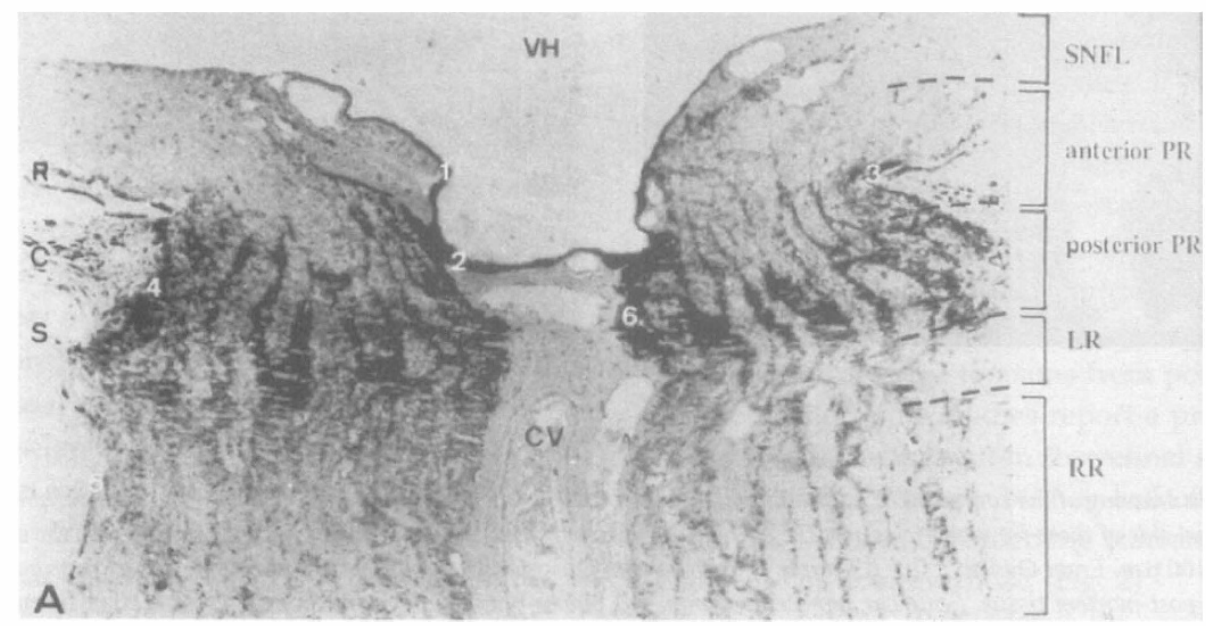

Fig. 4. Labelling for glial fibrillary acidic protein (GFAP) in the normal human optic nerve head. Note the heavy labelling in the prelaminar (anterior $P R$ and posterior $P R$ ) and laminar (LR) regions. SNFL, superficial nerve fibre layer; RR, retrolaminar region. From Trivino et al. ${ }^{49}$ 


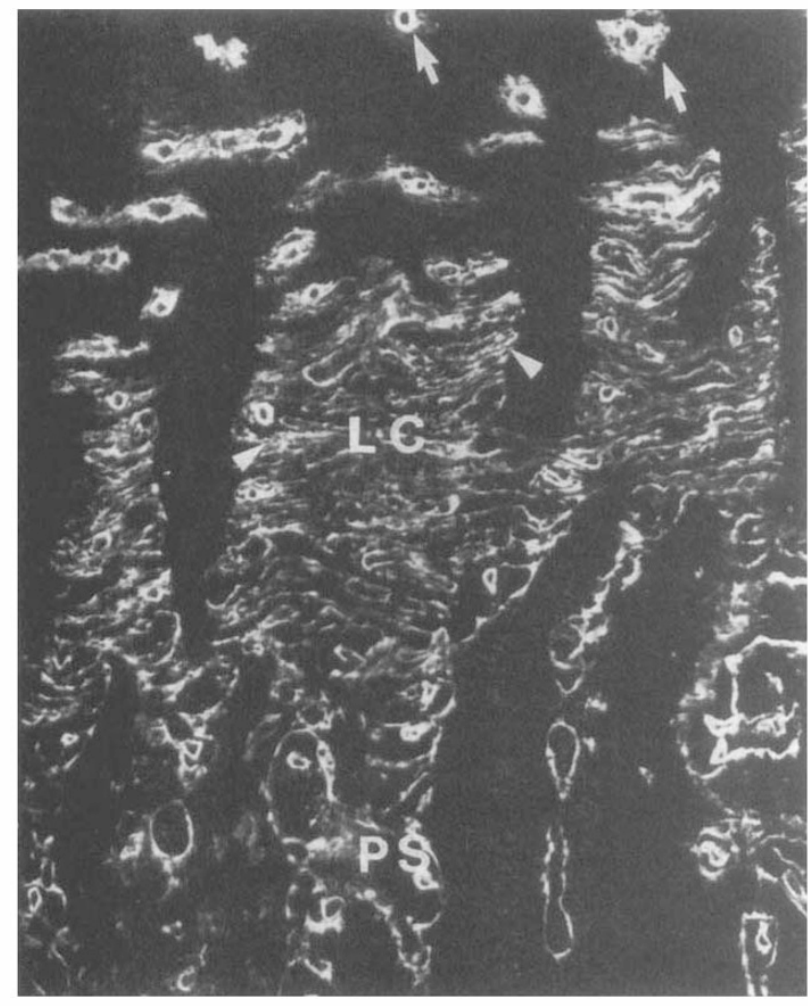

Fig. 5. Immunofluorescence staining for collagen type IV in a sagittal section of normal optic nerve head of a 49-year-old (x190). Arrows in the prelaminar region show staining around blood vessels. LC, lamina cribrosa; PS, pial septa. From Hemandez. ${ }^{52}$

Astrocytes in the optic nerve head: a common pathway for axon damage in glaucoma?

Astrocytes are the major cell type in the optic nerve head and are vital for retinal ganglion cell health. In the retina, they invest retinal ganglion cell axons as they leave the cell body ${ }^{39}$ and are the basis for the striations seen clinically in the retinal nerve fibre layer. ${ }^{40}$ They help maintain the extracellular environment and possess uptake mechanisms for the removal of potassium and glutamate from the extracellular space $e^{41-44}$ as well as providing neurotrophic support for adjacent neurons. ${ }^{45,46}$
At each level in the optic nerve head, astrocytes are organised to support axons in their passage from the eye to the optic nerve. In the prelaminar (choroidal) part of the lamina cribrosa, they form glial tubes through which axons pass as they turn through $90^{\circ}$ to enter the scleral part of the cribrosa ${ }^{47-49}$ (Fig. 4). They are also important in maintaining the structural elements of the optic nerve head. ${ }^{49,50}$ Astrocytes surround the cribrosal beams and produce the collagens and elastins that comprise the core of the laminar beams ${ }^{51,52}$ (Fig. 5). They are ideally placed to integrate mechanical or ischaemic insults to the optic nerve that might initiate axon damage (Fig. 6). ${ }^{49}$

Astrocytes are subspecialised in this supportive role. Type 1 astrocytes are found throughout the optic nerve and have been subdivided on the basis of histochemical labelling for the neural cell adhesion molecule (N-CAM) and glial fibrillary acidic protein (GFAP). All astrocytes express GFAP, but type $1 \mathrm{~B}$ astrocytes (the predominant type in the optic nerve head) also express N-CAM whereas type $1 \mathrm{~A}$ do not. ${ }^{50}$ It has been suggested that type $1 \mathrm{~A}$ astrocytes provide structural support for the axons, with type $1 \mathrm{~B}$ cells providing a physiological interface between the vitreous connective and vascular tissues. ${ }^{50}$ Astrocytes are likely to act as a syncytium in the maintenance of extracellular metabolism; they are connected by gap junctions ${ }^{34}$ which facilitate spatial buffering of $\mathrm{K}^{+}$and $\mathrm{Ca}^{2+53}$

The importance of astrocytes for the maintenance of neuronal health is well illustrated in culture models in which a glial or astroglial substrate is important for cell survival. ${ }^{54}$ Astrocytes will regulate the extracellular environment, possibly facilitated via gap junctions between astrocytes and neurons. ${ }^{55}$

Since astrocytes are metabolically very active, they are vulnerable to physiological perturbations and are usually the first cells in any neuronal system to respond to injury. ${ }^{56}$ As such, astrocyte dysfunction could disrupt axoplasmic transport and initiate the changes in cribrosal physiology that are secondary to the mechanical effects

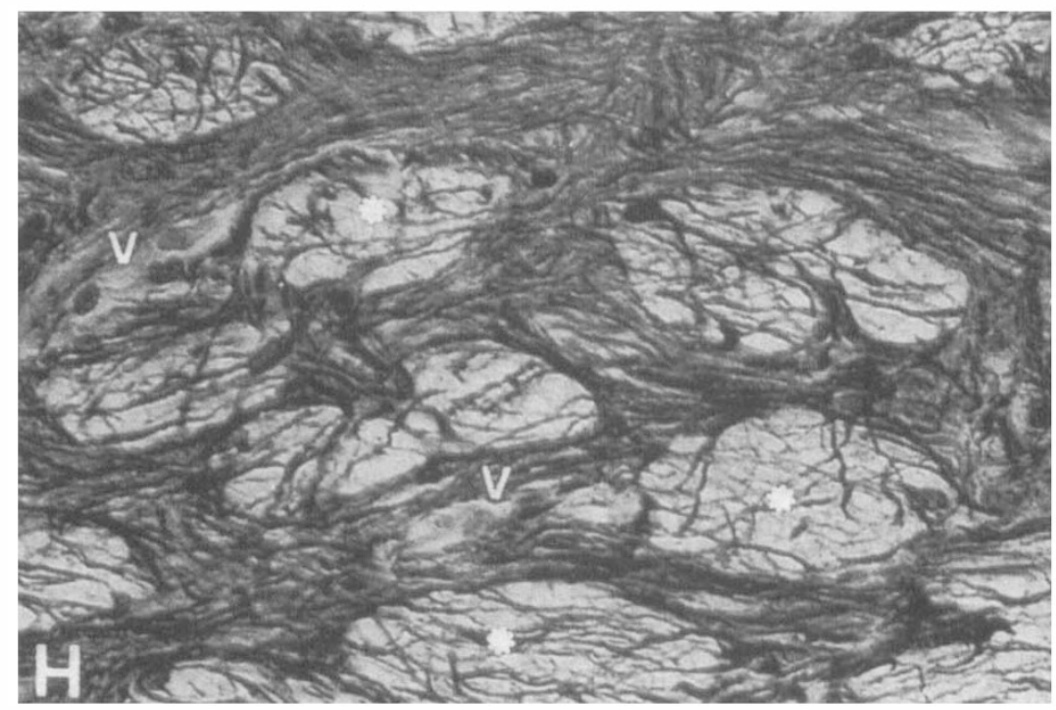

Fig. 6. GFAP labelling in astrocytes from the posterior part of the prelaminar region $(\times 600)$. The astrocytes are thick-bodied and form tubes (asterisk) in which the axon bundles run to enter the scleral lamina cribrosa. V, vessels lining the walls of the glial tubes. From Trivino et al. ${ }^{49}$ 


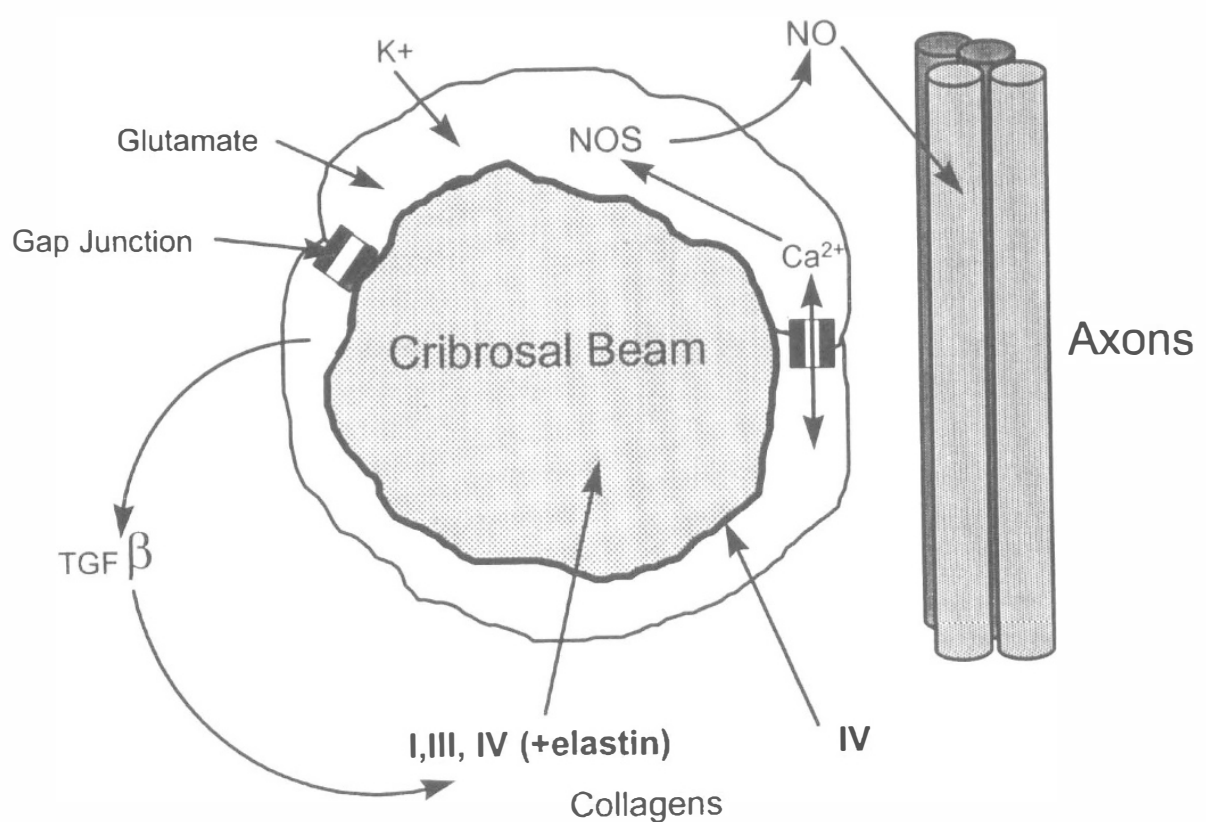

Fig. 7. Diagram summarising some of the interactions between the collagenous beams of the lamina cribrosa, astrocyte and axons. NO, nitric oxide; NOS, nitric oxide synthase.

of raised IOP or to ischaemic damage secondary to optic disc hypoperfusion. Increased IOP will cause the displacement of the lamina cribrosa and, since the astrocytes will be placed under mechanical shear stress, it is conceivable that this will stimulate altered collagen production by these cells. ${ }^{36}$ These mechanical forces have been studied in other systems such as the heart and endothelium and have been shown to alter gene expression. ${ }^{57,58}$ Similarly, hypoperfusion of the optic nerve head will compromise the astrocyte population resulting in physiological disruption ${ }^{59}$ and death. ${ }^{60}$

The hypothesis that significant disturbances of astrocyte metabolism may predispose to axon loss and initiate changes in cribrosal structure predicts that the collapse of the cribrosal beams, rather than initiating axon loss, may be as much the result of astrocyte fallout (and the concomitant axon loss). Recent work supports this central role for astrocytes in glaucomatous optic neuropathy. ${ }^{36}$ In the primate model of ocular hypertension, astrocytes round up and migrate from the core of the cribriform plates after only 4 weeks of raised $\mathrm{IOP}^{37}$ and express tenascin, an extracellular matrix molecule, as evidence of their activation. In human glaucoma, the organisation of astrocytes in the anterior part of the optic nerve shows marked disruption. The glial tubes of the choroidal lamina collapse accompanied by astrocyte activation and hypertrophy ${ }^{38}$ with increased expression of N-CAM and GFAP. In the laminar part of the nerve, astrocytes surrounding the cribrosal plates are reduced in size and appear to migrate into the nerve fibre layer bundles. ${ }^{38}$ The synthetic profile of these cells is altered with increased production of collagen IV in the laminar and prelaminar regions and elastin in the laminar zone $\mathrm{61,62}^{6}$ - changes which will contribute to the remodelling of the optic nerve head and lamina cribrosa so characteristic of glaucoma. Consistent with this, astrocytes in glaucomatous optic nerves produce high levels of TGF $\beta{ }^{63,64}$ an important cytokine that would regulate the changes in cribrosal structure and may be important in generating the reactive astrocyte phenotype. $^{65}$

During the early stages of activation, astrocytes may act not only by a compromise in their supportive functions but also by a direct toxic effect on the retinal ganglion cell axons. Optic nerve head astrocytes contain nitric oxide synthase (NOS), ${ }^{66}$ the enzyme responsible for the production of nitric oxide (NO). Since NOS activity is upregulated in human and experimental glaucoma, ${ }^{66}$ excessive levels of $\mathrm{NO}$ will predispose to retinal ganglion cell death ${ }^{67}$ and exacerbate any disruption of gapjunction-mediated intercellular communication in the astrocytes. ${ }^{68}$ Although there is, as yet, no evidence linking mechanical stress applied to astrocytes to alterations in NOS activity, there is strong evidence that this occurs in other systems such as vascular endothelium. ${ }^{69}$ Importantly, the reduction in NOS activity, either in culture ${ }^{70}$ or in a model of ocular hypertension, ${ }^{71}$ improves retinal ganglion cell survival.

One further implication of astrocyte dysfunction is that it should precede loss of retinal ganglion cell axons. In the rodent model of ocular hypertension, one of the earliest changes, which precedes any disruption of axoplasmic transport, is a reduction in connexin 43 labelling, one of the proteins involved in forming the gap junctions between astrocytes. ${ }^{72}$ The effect of this breakdown in intercellular communication is not entirely clear. It is possible that it limits neuronal damage, since in vitro studies have shown that gap junctions can facilitate cell death by transferring $\mathrm{Ca}^{2+}$ and oxidative stress to surrounding cells. ${ }^{73}$ Alternatively, the process may be harmful to surrounding neurons since uncoupling of gap junctions can increase necrotic cell death. ${ }^{74}$ The latter is more consistent with effects of disrupted gap junctions in neurodegenerative disorders 
such as Charcot Marie Tooth disease. ${ }^{75}$ The role of astrocytes in mediating $\mathrm{Ca}^{2+}$-related neuronal cell death has recently been reviewed. ${ }^{76}$

Finally, ischaemic damage to the optic nerve head sufficient to result in the loss of astrocytes should result in cupping of the optic disc. This has been reported in compressive optic neuropathy, anterior ischaemic neuropathy and Leber's optic neuropathy, ${ }^{77-79}$ - though it has not been reported as a consistent feature by others. ${ }^{80}$ Further quantitative studies of optic nerve head topography in these conditions are required to resolve this issue.

This review provides a limited overview of some of the astrocyte-axon-cribrosa interactions that might be relevant to glaucomatous optic neuropathy. Some of the more important pathways are summarised in Fig. 7 to highlight those interactions that may be relevant, therapeutically, for the modulation of retinal ganglion cell death in glaucoma. The true picture is almost certainly more complicated and involves other cell types. Thus, activated microglia have been demonstrated in human glaucomatous optic nerve heads ${ }^{81}$ and have been suggested to cause the degenerative changes such as peripapillary degeneration seen in glaucoma. Further work is required to elucidate the relative importance of these various pathways in the initiation of axon damage.

\section{References}

1. Anderson DR, Hendrickson A. Effect of intraocular pressure on rapid axonal transport in monkey optic nerve. Invest Ophthalmol Vis Sci 1974;13:771-83.

2. Hayreh SS, March W, Anderson DR. Pathogenesis of block of rapid orthograde axonal transport by elevated intraocular pressure. Exp Eye Res 1979;28:515-23.

3. Gaasterland D, Tanishima T, Kuwabara T. Axoplasmic flow during chronic experimental glaucoma. I. Invest Ophthalmol Vis Sci 1978;17:838-46.

4. Quigley H, Anderson D. The dynamics and location of axonal transport blockade by acute intraocular pressure elevation in primate optic nerve. Invest Ophthalmol Vis Sci 1976;15:606-16.

5. Quigley HA, Addicks EM. Chronic experimental glaucoma in primates. II. Effect of extended intraocular pressure on optic nerve head and axonal transport. Invest Ophthalmol Vis Sci 1980;19:137-52.

6. Lindsay RM, Wiegand SJ, Altar CA, DiStefano PS. Neurotrophic factors: from molecule to man. Trends Neurosci 1994;17:182-90.

7. Garcia-Valenzuela E, Shareef S, Walsh J, Sharma SC. Programmed cell death of retinal ganglion cells during experimental glaucoma. Exp Eye Res 1995;61:33-44.

8. Quigley HA, Nickells RW, Kerrigan LA, Pease ME, Thibault DJ, Zack DJ. Retinal ganglion cell death in experimental glaucoma and after axotomy occurs by apoptosis. Invest Ophthalmol Vis Sci 1995;36:774-86.

9. Kerrigan LA, Zack DJ, Quigley HA, Smith SS, Pease ME. Tunel-positive ganglion cells in human primary open angle glaucoma. Arch Ophthalmol 1997;115:1031-5.

10. Quigley HA, Addicks EM, Green WR. Optic nerve damage in human glaucoma. III. Quantitative correlation of nerve fiber loss and visual defect in glaucoma, ischemic neuropathy, papilledema and toxic neuropathy. Arch Ophthalmol 1982;100:135-46.

11. Quigley H, Addicks E. Regional differences in the structure of the lamina cribrosa and their relation to glaucomatous optic nerve damage. Arch Ophthalmol 1981;99:137-43.
12. Quigley HA, Addicks EM, Green WR, Maumenee AE. Optic nerve damage in human glaucoma. II. The site of injury and susceptibility to damage. Arch Ophthalmol 1981;99:635-49.

13. Quigley HA, Hohman RM, Addicks EM, Massof RW, Green WR. Morphologic changes in the lamina cribrosa correlated with neural loss in open-angle glaucoma. Am J Ophthalmol 1983;95:673-91.

14. Morgan JE, Jeffery G, Foss AJ. Axon deviation in the human lamina cribrosa. Br J Ophthalmol 1998;82:680-3.

15. Ogden TE, Duggan J, Danley K, Wilcox M, Minkler DS. Morphometry of nerve bundle pores in the optic nerve head of the human. Exp Eye Res 1988;46:559-68.

16. Dichtl A, Jonas JB, Naumann GO. Course of the optic nerve fibres through the lamina cribrosa in human eyes. Graefes Arch Clin Exp Ophthalmol 1996;234:581-5.

17. Quigley HA, Addicks EM. Quantitative studies of retinal nerve fiber layer defects. Arch Ophthalmol 1982;100:807-14.

18. Wolff E, Penmann G. The position occupied by the peripheral retinal fibres in the nerve-fibre layer and at the nerve head. Acta Concillium Ophthalmol 1951;16:625-35.

19. Radius RL, Anderson DR. The course of axons through the retina and optic nerve head. Arch Ophthalmol 1979;97:1154-8.

20. Minckler DS. The organization of nerve fibre bundles in the primate optic nerve head. Arch Ophthalmol 1980;98:1630-6.

21. Fitzgibbon T, Taylor SF. Retinotopy of the human retinal nerve fibre layer and optic nerve head. J Comp Neurol 1996;375:238-51.

22. Ogden TE. Nerve fiber layer of the macaque retina: retinotopic organization. Invest Ophthalmol Vis Sci 1983;24:85-98.

23. Naito J. Retinogeniculate fibers in the monkey optic nerve: a demonstration of the fiber pathways by retrograde axonal transport of WGA-HRP. J Comp Neurol 1989;284:174-86.

24. Crichton A, Drance SM, Douglas GR, Schulzer M. Unequal intraocular pressure and its relation to asymmetric visual field defects in low tension glaucoma. Ophthalmology 1989;96:1312-4.

25. Cartwright MJ, Anderson DR. Correlation of asymmetric damage with asymmetric intraocular pressure in normaltension glaucoma (low-tension glaucoma). Arch Ophthalmol 1988;106:898-900.

26. Wang L, Cioffi GA, Van Buskirk EM. The vascular pattern of the optic nerve and its potential relevance in glaucoma. Curr Opin Ophthalmol 1998;9:24-9.

27. Phelps CD, Corbett JJ. Migraine and low tension glaucoma: a case-controlled study. Invest Ophthalmol Vis Sci 1985;26:1105-8.

28. Graham SL, Drance SM, Wijsman K, Mikelberg FS, Douglas GR. Nocturnal hypotension in glaucoma patients. Invest Ophthalmol Vis Sci 1993;34:S1286.

29. Kerr J, Nelson P, O'Brien C. A comparison of ocular blood flow in untreated primary open-angle glaucoma and ocular hypertension. Am J Ophthalmol 1998;126:42-51.

30. O'Brien C, Butt Z, Ludlam C, Dektova P. Activation of the coagulation cascade in untreated primary open angle glaucoma. Ophthalmology 1996;104:725-30.

31. Orgul S, Cioffi G, Bacon D, Van Buskirk E. An endothelin-1induced model of chronic optic nerve ischemia in rhesus monkeys. J Glaucoma 1996;5:135-8.

32. Cioffi GA, Orgul S, Onda E, Bacon DR, Van Buskirk EM. An in vivo model of chronic optic nerve ischemia: the dosedependent effects of endothelin-1 on the optic nerve microvasculature. Curr Eye Res 1995;14:1147-53.

33. Kaiser HJ, Flammer J, Wenk M, Luscher T. Endothelin-1 plasma levels in normal-tension glaucoma: abnormal response to postural changes. Graefes Arch Clin Exp Ophthalmol 1995;233:484-8.

34. Quigley HA. Gap junctions between optic nerve head astrocytes. Invest Ophthalmol Vis Sci 1977;16:582-5.

35. Anderson DR, Hoyt WF, Hogan M. The fine structure of the astroglia in the human optic nerve and optic nerve head. Trans Ophthalmol Soc Am 1969;65:274-305. 
36. Hernandez MR, Pena JD. The optic nerve head in glaucomatous optic neuropathy. Arch Ophthalmol 1997;115:389-95.

37. Hernandez MR, Hanninen LA, Hubbard WC, Kaufman PL, Weber AJ. Astrocyte responses in the lamina cribrosa in pressure dependent glaucoma in monkeys. Invest Ophthalmol Vis Sci 1995;36:S606.

38. Varela HJ, Hernandez MR. Astrocyte responses in human optic nerve head with primary open-angle glaucoma. J Glaucoma 1997;6:303-13.

39. Stone J, Makarov F, Hollander H. The glial ensheathment of the soma and axon hillock of retinal ganglion cells. Vis Neurosci 1995;12:273-9.

40. Radius RL, de Bruin J. Anatomy of the retinal nerve fiber layer. Invest Ophthalmol Vis Sci 1981;21:745-9.

41. Waniewski RA, Martin DL. Exogenous glutamate is metabolised to glutamine and exported by rat primary astrocyte cultures. J Neurochem 1986;47:304-13.

42. Farinelli SE, Nicklas WJ. Glutamate metabolism in rat cortical astrocyte cultures. J Neurochem 1992;58:1905-15.

43. Swanson RE. Astrocyte glutamate uptake during chemical hypoxia in vitro. Neurosci Lett 1992;147:143-6.

44. Ransom BR, Fern R. Does astrocytic glycogen benefit axon function and survival in CNS white matter during glucose deprivation? Glia 1997;21:134-41

45. Goss JR, O'Malley ME, Zou L, Styren SD, Kochanek PM, DeKosky ST. Astrocytes are the major source of nerve growth factor upregulation following traumatic brain injury in the rat. Exp Neurol 1998;149:301-9.

46. Wu VW, Nishiyama N, Schwartz JP. A culture model of reactive astrocytes: increased nerve growth factor synthesis and reexpression of cytokine responsiveness. J Neurochem 1998;71:749-56.

47. Anderson DR. Ultrastructure of human and monkey lamina cribrosa and optic nerve head. Arch Ophthalmol 1969;82:800-14.

48. Elkington AR, Inman CB, Steart DV, Weller RO. The structure of the lamina cribrosa of the human eye: an immunocytochemical and electron microscopic study. Eye 1990;4:42-57.

49. Trivino A, Ramirez JM, Salazar JJ, Ramirez AI, GarciaSanchez J. Immunohistochemical study of human optic nerve head astroglia. Vision Res 1996;36:2015-28.

50. Ye H, Hernandez MR. Heterogeneity of astrocytes in human optic nerve head. J Comp Neurol 1995;362:441-52.

51. Hernandez MR, Wang N, Hanley N, Neufeld A. Localization of collagen types I and IV mRNAs in human optic nerve head by in situ hybridization. Invest Ophthalmol Vis Sci 1991;32:2169-77.

52. Hernandez MR. Extracellular matrix molecules of the lamina cribrosa: a pressure-sensitive connective tissue. J Glaucoma 1993;2:50-7.

53. Lee SH, Kim WT, Cornell-Bell AH, Sontheimer H. Astrocytes exhibit regional specificity in gap-junction coupling. Glia 1994;11:315-25.

54. Rosenberg PA. Accumulation of extracellular glutamate and neuronal death in astrocyte-poor cortical cultures exposed to glutamine. Glia 1991;4:91-100.

55. Dermietzel R, Spray DC. Gap junctions in the brain: where, what type, how many and why? Trends Neurosci 1993;16:186-92.

56. Eddleston M, Mucke L. Molecular profile of reactive astrocytes: implications for their role in neurologic disease. Neuroscience 1993;54:15-36.

57. Chiu JJ, Wung BS, Hsieh HJ, Lo LW, Wang DL. Nitric oxide regulates shear stress-induced early growth response. 1 . Expression via the extracellular signal-regulated kinase pathway in endothelial cells. Circ Res 1999;85:238-46.

58. Yamamoto K, Dang QN, Kelly RA, Lee RT. Mechanical strain suppresses inducible nitric-oxide synthase in cardiac myocytes. J Biol Chem 1998;273:11862-6.

59. Swanson RA, Farrell K, Simon RP. Acidosis causes failure of astrocyte glutamate uptake during hypoxia. J Cereb Blood Flow Metab 1995;15:417-24.
60. Swanson RA, Farrell K, Stein BA. Astrocyte energetics, function, and death under conditions of incomplete ischemia: a mechanism of glial death in the penumbra. Glia 1997;21:142-53.

61. Hernandez MR, Ye H, Roy S. Collagen type IV gene expression in human optic nerve heads with primary open angle glaucoma. Exp Eye Res 1994;59:41-51.

62. Hernandez MR, Yang J, Ye H. Activation of elastin mRNA expression in human optic nerve heads with primary open angle glaucoma. J Glaucoma 1994;3:214-25.

63. Pena JO, Taylor AW, Ricard CS, Vidal I, Hernandez MR. Transforming growth factor beta isoforms in human optic nerve heads. Br J Ophthalmol 1999;83:209-18.

64. Cordeiro MF, Khaw PT. The healing optic nerve in glaucoma: transforming growth factor beta and optic nerve head remodelling. Br J Ophthalmol 1999;83:132.

65. Flanders KC, Ren RF, Lippa CF. Transforming growth factorbetas in neurodegenerative disease. Prog Neurobiol 1998;54:71-85.

66. Neufeld AH, Hernandez MR, Gozalez M. Nitric oxide synthase in the human glaucomatous optic nerve head. Arch Ophthalmol 1997;115:497-503.

67. Dawson TM, Dawson VL. Nitric oxide: actions and pathological roles. Neuroscientist 1995;1:7-18.

68. Bolanos JP, Medina JM. Induction of nitric oxide synthase inhibits gap junction permeability in cultured rat astrocytes. J Neurochem 1996;66:2091-9.

69. Ziegler T, Silacci P, Harrison VJ, Hayoz D. Nitric oxide synthase expression in endothelial cells exposed to mechanical forces. Hypertension 1998;32:351-5.

70. Morgan J, Caprioli J, Koseki Y. Nitric oxide mediates excitotoxic and anoxic damage in rat retinal ganglion cells cocultured with astroglia. Arch Ophthalmol 1999;117:1524-9.

71. Neufeld AH, Sawada A, Becker B. Inhibition of nitric-oxide synthase 2 by aminoguanidine provides neuroprotection of retinal ganglion cells in a rat model of chronic glaucoma. Proc Natl Acad Sci USA 1999;96:9944-8.

72. Johnson EC, Deppmeier LM, Wentzien SK, Hsu I, Morrison JC. Chronology of optic nerve head and retinal responses to elevated intraocular pressure. Invest Ophthalmol Vis Sci 2000:41:431-42.

73. Lin JH, Weigel H, Cotrina ML, et al. Gap-junction-mediated propagation and amplification of cell injury. Nature Neurosci 1998;1:494-500.

74. Blanc EM, Bruce-Keller AJ, Mattson MP. Astrocytic gap junctional communication decreases neuronal vulnerability to oxidative stress-induced disruption of $\mathrm{Ca}^{2+}$ homeostasis and cell death. J Neurochem 1998;70:958-70

75. Bergoffen J, Scherer SS, Wang S, et al. Connexin mutations in $\mathrm{X}$-linked Charcot-Marie-Tooth disease. Science 1993;262:2039-42.

76. Budd SL, Lipton SA. Calcium tsunamis: do astrocytes transmit cell death messages via gap junctions during ischemia? Nature Neurosci 1998;1:431-2.

77. Bianchi-Marzoli S, Rizzo JF, Brancato R, Lessell S. Quantitative analysis of optic disc cupping in compressive optic neuropathy. Ophthalmology 1995;102:436-40.

78. Orgul S, Gass A, Flammer J. Optic disc cupping in arteritic anterior ischemic optic neuropathy. Ophthalmologica 1994;208:336-8.

79. Ortiz RG, Newman NJ, Manoukian SV, Diesenhouse MC, Lott MT, Wallace DC. Optic disk cupping and electrocardiographic abnormalities in an American pedigree with Leber's hereditary optic neuropathy. Am J Ophthalmol 1992;113:561-6.

80. Quigley H, Anderson DR. Cupping of the optic disc in ischemic optic neuropathy. Trans Am Acad Ophthalmol Otolaryngol 1977;83:755-62.

81. Neufeld AH. Microglia in the optic nerve head and the region of parapapillary chorioretinal atrophy in glaucoma. Arch Ophthalmol 1999;117:1050-6. 